\title{
Epidermolytic Acanthoma
}

National Cancer Institute

\section{Source}

National Cancer Institute. Epidermolytic Acanthoma. NCI Thesaurus. Code C27516.

A benign epithelial verrucous lesion of the skin. Morphologically, it is characterized by the presence of epidermolytic hyperkeratosis and papillomatosis. 